\title{
AULAS COM INTERAÇÃO: ENSINANDO (E APRENDENDO) LÍNGUA PORTUGUESA E CULTURA BRASILEIRA NA COREIA DO SUL
}

\author{
CLASES CON INTERACCIÓN: LA ENSEÑANZA (Y EL APRENDIZAJE) DEL \\ IDIOMA PORTUGUÉS Y DE LA CULTURA BRASILEÑA EN COREA DEL SUR
}

\author{
COMMUNICATIVE CLASSES: TEACHING (AND LEARNING) \\ PORTUGUESE AND BRAZILIAN CULTURE IN SOUTH KOREA
}

Denis Leandro FRANCISCO ${ }^{1}$

\begin{abstract}
RESUMO: De acordo com a perspectiva dos próprios estudantes coreanos, "qual a maior dificuldade para aprender Português" e "que tipo de aula é melhor para aprender Português"? Este artigo analisa esses dois importantes aspectos do perfil dos estudantes do curso de Estudos Brasileiros de uma das mais prestigiadas universidades da Coreia do Sul na área de Estudos Estrangeiros: Hankuk University of Foreign Studies. A partir do levantamento desses dados notadamente relevantes para o processo de aquisição de língua estrangeira, busca-se refletir sobre tais aspectos com vistas a contribuir para o aprimoramento do ensino-aprendizagem de português como língua estrangeira e de cultura brasileira para estudantes coreanos. Os resultados obtidos indicam que aspectos gramaticais são percebidos pelos estudantes coreanos como o maior dificultador para o desenvolvimento da sua proficiência em língua portuguesa e que, por outro lado, o Ensino Comunicativo atende à expectativa dos estudantes por uma aula que promova o protagonismo do aprendiz de língua estrangeira, levando-o a apropriar-se do seu próprio processo de aprendizagem.
\end{abstract}

PALAVRAS-CHAVE: PLE. Ensino Comunicativo. Estudos brasileiros. HUFS. Coreia do Sul

RESUMEN: Según la perspectiva de los estudiantes coreanos, "¿Cuál es el peor obstáculo en su proceso de aprendizaje del idioma portugués" y "¿Qué tipo de clase facilita el aprendizaje de ese idioma?". Este artículo analiza estos dos importantes aspectos del perfil de los estudiantes del curso de Estudios Brasileños en una de las más prestigiosas universidades de Corea del Sur en el área de Estudios Extranjeros: Hankuk University of Foreign Studies. Del estudio de estos datos de especial relevancia para el proceso de adquisición de la lengua extranjera, tratamos de reflexionar sobre estos aspectos con el fin de contribuir a la mejora de la enseñanza-aprendizaje del portugués como lengua extranjera y de la cultura brasileña a los estudiantes coreanos. Los resultados indican que los aspectos gramaticales son percibidos por los estudiantes coreanos como el mayor impedimento para el desarrollo de su competencia en el idioma portugués $y$, por otro lado, la Enseñanza Comunicativa cumple con las expectativas de los estudiantes hacia una clase que promueve la centralidad del

${ }^{1}$ Hankuk University of Foreign Studies (HUFS), Global Campus, Yongin - South Korea. Assistant Professor, PhD. Department of Brazilian Studies. ORCID: 〈https://orcid.org/0000-0001-5947-8832>. Email: denisleandro@outlook.com 
aprendiz de lengua extranjera, llevándolo a apropiarse de su propio proceso de aprendizaje.

PALABRAS CLAVE: PLE. Enseñanza comunicativa. Estudios brasileños. HUFS. Corea del Sur

ABSTRACT: According to the Korean students' own perspective, "what is the greatest difficulty in learning Portuguese" and "what kind of class is best to learn Portuguese"? This article analyzes these two important aspects of the profile of students who are learning Brazilian Portuguese as a foreign language at Hankuk, one of South Korea's most prestigious universities in Foreign Studies field. Based on collection of some data considered relevant for the acquisition process of a foreign language, we aim at reflecting on these aspects to contribute to the improvement of the teaching-learning process of Brazilian Portuguese as a foreign language and Brazilian culture to Korean students. The results indicate that grammatical aspects are perceived by Korean students as the major obstacle to the development of their proficiency and that, on the other hand, Communicative Teaching meets the expectation of Korean students for a class that leads them to take ownership of their own learning process as protagonists.

KEYWORDS: PFL. Communicative approach. Brazilian studies. HUFS. South Korea.

\section{Introdução}

Como é a universidade em que os estudantes aprendem português na Coreia do $\mathrm{Sul}^{2}$ ? Fundada em 1952, a Universidade Coreana de Estudos Estrangeiros (HUFS) é historicamente reconhecida, tanto na Coreia do Sul quanto internacionalmente, pela sua qualidade e credibilidade acadêmica. Em 2016, a instituição foi avaliada como a $10^{\mathrm{a}}$ universidade mais respeitável da Coreia do Sul de acordo com uma recente pesquisa realizada pelo Joong-Ang Daily University Rankings ${ }^{3}$ nas 69 principais universidades do país que oferecem cursos de graduação de 4 anos em mais de 6 das seguintes áreas do conhecimento: Humanidades, Ciências Sociais, Ciências Naturais, Engenharia, Medicina e Esportes e Artes.

Em outra pesquisa, compilada e divulgada em 2016 pelo Chosun Ilbo (periódico diário de maior circulação do país) e desenvolvida pela Quacquarelli Symonds - "QS" (uma companhia britânica especializada em educação e internacionalização), a HUFS aparece em primeiro lugar na lista de universidades sul-coreanas "sem faculdades de

${ }^{2}$ Há apenas três universidades que oferecem graduação na área de português na Coreia do Sul: Hankuk, Busan e Dankook University.

${ }^{3}$ Disponível em: <http://www.hufsnews.co.kr/news/articleView.html?idxno=14074>. Acesso em: 07 out. 2017. 
Medicina", figurando ainda entre as 10 mais renomadas universidades da Ásia. A pesquisa foi realizada em 517 universidades em 17 países e regiões asiáticas, incluindo, além da Coreia do Sul, Japão, China, Cingapura e Hong Kong, conforme mostra a figura 1, a seguir:

Figura 1: Pesquisa aplicada - Países

Comprehen sive, large universities with no medical school

\begin{tabular}{|c|l|l|}
\hline Ranking & \multicolumn{1}{|c|}{ University } & \multicolumn{1}{|c|}{ Country } \\
\hline 1 & The Hong Kong University of Science and Technology & Hong Kong \\
\hline 2 & University of Science and Technology of China & China \\
\hline 3 & The Hong Kong Polytechnic University & Hong Kong \\
\hline 4 & Beijing Normal University & China \\
\hline 5 & Waseda University & Japan \\
\hline 6 & Universiti Teknologi Malaysia & Malaysia \\
\hline 7 & Shanghai University & China \\
\hline 8 & Tianjin University & China \\
\hline 9 & Hankuk University of For eign Studies(HUFS) & South Kor ea \\
\hline 10 & East China Normal University & China \\
\hline
\end{tabular}

Source : 2016 Chosun Ilbo-QS Asia University Rankings

Fonte: Disponível em: <http://www.hufsnews.co.kr/news/articleView.html?idxno=13837>. Acesso em: 07 out. 2017.

Em termos de internacionalização, ainda de acordo com a pesquisa da QS, a HUFS superou todas as universidades sul-coreanas e ocupou a $13^{\mathrm{a}}$ posição entre as universidades asiáticas, como mostra a figura 2:

Figura 2: Posições

The aggregate ranking of Asia universities in the category of intern ationalization

\begin{tabular}{|c|l|l|}
\hline Ranking & \multicolumn{1}{|c|}{ University } & \multicolumn{1}{|c|}{ Country } \\
\hline 1 & City University of Hong Kong & Hong Kong \\
\hline 2 & The University of Hong Kong & Hong Kong \\
\hline 3 & The Hong Kong University of Science and Technology & Hong Kong \\
\hline 4 & Nanyang Technological University(NTU) & Singapore \\
\hline 5 & Universiti Brunei Darussalam (UBD) & Brunei \\
\hline 6 & National University of Singapore (NUS) & Singapore \\
\hline 7 & Universiti Malaya (UM) & Malaysia \\
\hline 8 & The Chinese University of Hong Kong (CUHK) & Hong Kong \\
\hline 9 & Lingnan University, Hong Kong & Hong Kong \\
\hline 10 & Singapore Management University & Singapore \\
\hline 13 & Hankuk Univer sity of For eign Studies(HUFS) & South Kor a \\
\hline 18 & Hanyang University & South Korea \\
\hline 25 & Korea University & South Korea \\
\hline 32 & Yonsei University & South Korea \\
\hline Source $: 2016$ Chosun Ilbo-QS Asia University Rankings & \\
\hline
\end{tabular}

Fonte: Disponível em: <http://www.hufsnews.co.kr/news/articleView.html?idxno=13837>. Acesso em: 07 out. 2017. 
É, portanto, do estudante proveniente desse contexto acadêmico específico que trataremos neste artigo, ao analisarmos as respostas sobre o seu próprio processo de aprendizagem de português como língua estrangeira. A pesquisa foi desenvolvida com estudantes do nível intermediário de português do Departamento de Estudos Brasileiros da HUFS, Global Campus, localizado na região metropolitana de Seul. Com vistas ao aprimoramento do ensino-aprendizagem de português para estudantes coreanos e através da análise de dados coletados por meio de questionário especificamente estruturado para o público-alvo da pesquisa, este artigo identifica: a) quais aspectos do processo de ensino-aprendizagem da língua portuguesa os estudantes consideram mais difíceis e; b) quais abordagens/estratégias para o ensino-aprendizagem de português como língua estrangeira (PLE) os estudantes consideram que melhor atendem às suas necessidades.

\section{A pesquisa: "Perfil do estudante do curso de Estudos Brasileiros da HUFS"}

O questionário de pesquisa "Perfil do estudante do curso de Estudos Brasileiros da HUFS" foi aplicado para todos os estudantes do nível intermediário de português do curso de Estudos Brasileiros, totalizando 41 respondentes. Esse público-alvo da pesquisa foi selecionado com base em dois critérios objetivos: a) os estudantes desse nível podem já compreender as perguntas e respondê-las de forma autônoma; b) os estudantes desse nível têm já um autoconhecimento razoável do seu próprio processo de aprendizagem de português como língua estrangeira no contexto universitário.

Para assegurar a confiabilidade das respostas dadas, os estudantes responderam ao questionário anonimamente, de forma presencial e, em seguida, o instrumento foi recolhido pelo próprio professor. O instrumento de pesquisa foi estruturado em três seções: "Informações pessoais", "Sobre o curso de Estudos Brasileiros" e "Sobre Língua Portuguesa". Esta última seção é composta por 10 itens, 7 completamente fechados e 3 com a opção “Outro. Qual?”. Neste artigo, analisamos as respostas dadas a duas perguntas que fazem parte dessa terceira seção - que, como indica o título, é composta por itens voltados para aferir informações especificamente relacionadas ao processo de ensino-aprendizagem do português no contexto universitário coreano.

\section{Coreanos acham difícil aprender português?}


O item 17 da seção "Sobre Língua Portuguesa" faz a seguinte pergunta aos estudantes coreanos:

Para você, qual a maior dificuldade para aprender Português? (numere 1, 2 ou 3 opções, comecando da que você acha mais difícil).

[__ ] Gramática

[___ Vocabulário

[___ Pronúncia

[___ Escrever

[__ $]$ Ler

[___ Ouvir/Escutar

[___ Falar/Conversar

[___ Aspectos culturais

[____ _ _u não me sinto confortável para participar nas aulas (I do not feel comfortable taking part in classes)

[___ Outro. Qual?

Quase metade dos estudantes (49\%) apontou Gramática como a sua maior dificuldade para aprender português. Se considerarmos a distância entre a língua de partida desses estudantes (coreano) e a língua-alvo (português do Brasil), esse dado não configura exatamente uma surpresa.

O alfabeto da língua coreana, chamado Hangeul, é composto por 24 letras, sendo 10 vogais e 14 consoantes que sofrem alterações e elevam o número de caracteres do alfabeto para $40 \mathrm{em}$ sua totalidade. Ao invés de serem escritas sequencialmente como as letras do alfabeto latino, as letras do Hangeul são organizadas em blocos de sílabas chamados de Jamo. Ainda que o alfabeto coreano seja tido como bastante fácil de ser aprendido, o fato de se tratar de um alfabeto constituído por letras completamente diferentes das que compõem o nosso alfabeto latino, aliado à gramática particularíssima do idioma, fazem do coreano uma língua muito distante da língua portuguesa no que concerne à sintaxe, ao vocabulário, à morfologia e à fonética. Para uma breve exemplificação, apresentamos, a seguir, um mesmo enunciado simples em português (A) e em coreano (B):

\section{(A)Eu sou brasileiro, mas moro na Coreia do Sul.$$
\text { (B) 나는 브라질 사람 이지만 한국에 살고 있다. }
$$

Vejamos cada um dos constituintes sintáticos na ordem em que aparecem no enunciado em coreano: 
나 (sujeito - “eu”) 는 (partícula de tópico/ênfase)

브라질 사람 (predicado - "brasileiro")

이 (verbo - "ser”) 지만 (conjunção adversativa - "mas")

한국에 (predicado com preposição de lugar - "na Coreia")

살고 있다 (verbo "viver" conjugado no "gerúndio")

Mesmo a partir de um enunciado simples como o apresentado em (A) e (B), não é difícil perceber a distância da língua coreana em relação à língua portuguesa, especialmente em relação à estruturação e ao funcionamento gramatical: existência e obrigatoriedade de partículas de tópico que não estão presentes no enunciado em língua portuguesa; diferente posicionamento dos elementos sintáticos (o verbo "ser", em coreano, vem após o predicado "brasileiro"); preposição de lugar acoplada ao predicado ("na Coreia"); e, por fim, o verbo "viver" no gerúndio, indicando ação atual em coreano, ao invés do verbo flexionado no presente simples, como ocorre para indicar a mesma ação atual no enunciado em língua portuguesa ("moro" ou "vivo"). A seguir, o gráfico 01 permite visualizar as respostas dos estudantes à pergunta "Para você, qual a maior dificuldade para aprender Português?”:

Gráfico 1: Visualização das respostas

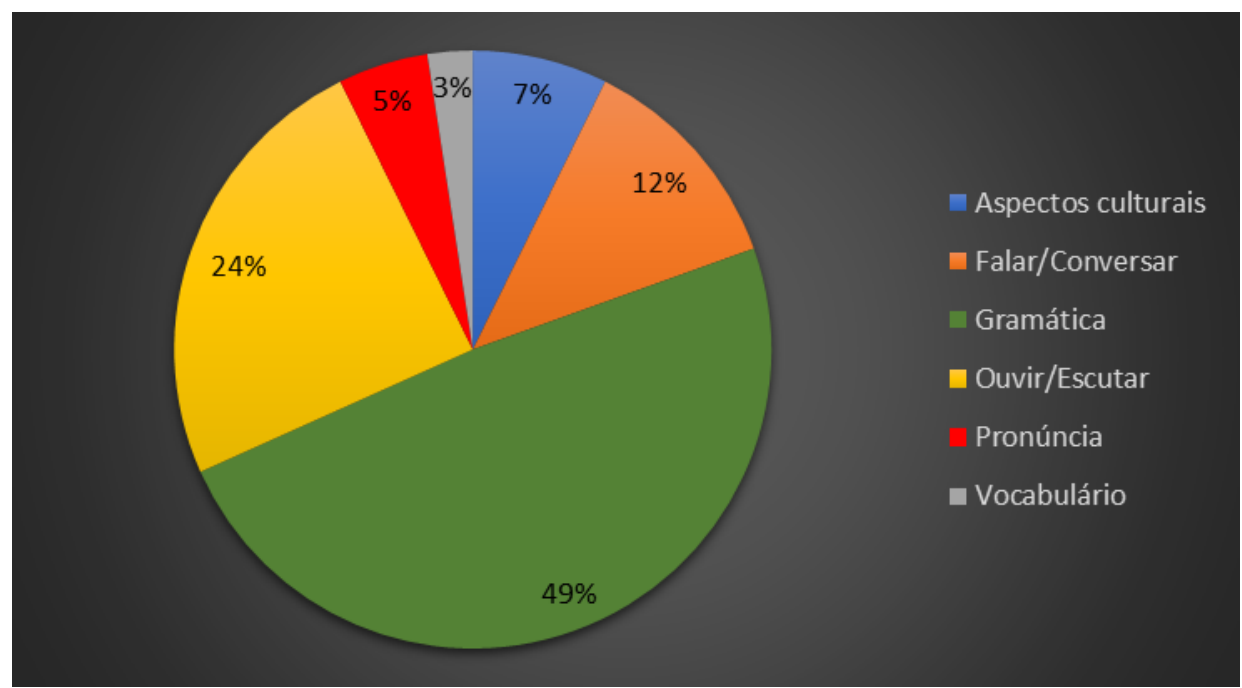

Fonte: Autoria própria 
A opção considerada como a $2^{\mathrm{a}}$ maior dificuldade dos estudantes foi “Ouvir/Escutar", indicada por 24\% dos respondentes. O desenvolvimento da habilidade de compreensão oral mostra-se, de fato, como um dos objetivos mais desafiadores da aula de português para coreanos nesse contexto universitário, tanto para os alunos quanto para os professores.

A primeira razão que podemos aventar para essa dificuldade constatada a partir dos dados da pesquisa é a complexidade de se compreender um falante de língua estrangeira (sobretudo de uma língua estrangeira considerada distante) em seu ritmo natural de fala. Essa hipótese tem relação direta com o aspecto da língua portuguesa que os estudantes consideram como a sua maior dificuldade para aprender português: a gramática. Afinal, a compreensão oral é fortemente afetada pelo nível de conhecimento que o estudante tem da gramática da língua (sua lógica sintática), ainda que a compreensão oral também dependa do domínio que o estudante tem do vocabulário, da fonética e de um sem-número de aspectos socioculturais que conformam uma língua. Compreender um texto oral em língua estrangeira é também compreender a gramática desse texto em língua estrangeira.

A segunda hipótese que levantamos para a dificuldade em "Ouvir/Escutar", apontada pelos participantes relaciona-se à baixa exposição do estudante coreano a situações em que a modalidade oral da língua portuguesa é empregada. Essa baixa exposição pode estar relacionada a diversos fatores, como a relativamente restrita oferta de atividades culturais em português na Coreia do Sul e o pouco contato dos estudantes coreanos com falantes nativos de língua portuguesa, já que, apesar de haver uma comunidade brasileira $^{4}$ na Coreia do Sul, a interação entre brasileiros e os estudantes coreanos de língua portuguesa não é constante.

\section{Como os estudantes coreanos preferem aprender português?}

No item 14 da seção "Sobre Língua Portuguesa", é feita a seguinte pergunta aos estudantes coreanos:

\footnotetext{
4 “De acordo com dados do Sistema de Imigração da Coreia do Sul, há cerca de 1.400 brasileiros no país (2016). Desse total, estima-se que 50\% esteja na região metropolitana de Seul e 20\% na Região Sul, próximo à cidade de Busan e na ilha de Geoje.”. Disponível em: <https://sistemas.mre.gov.br/kitweb/datafiles/Seul/ptbr/file/Morando\%20na\%20Coreia\%20do\%20Sul\%20-\%20jul\%202012\%20\%20atualiza\%C3\%A7\%C3\%A3o.pdf>. Acesso em: 07 out. 2017.
} 
Para você, que tipo de aula é melhor para aprender Português? (numere 1, 2 ou 3 opções, comecando da que você acha melhor)

\section{[____ Aula com exercícios de gramática}

[____ Aula com exercícios de leitura

[___ A Aula com vídeos e áudios sobre cultura brasileira

[___ Aula com diálogos, debates e apresentações entre os alunos

[____ Aula com exercícios de tradução (Português-Coreano e CoreanoPortuguês)

Novamente, quase metade dos estudantes (49\%) indicou a mesma resposta: eles preferem "aula com diálogos, debates e apresentações entre os alunos". Consideramos que o descritor dessa opção apresentada pelo questionário aproxima-se do que chamamos de ensino comunicativo (EC) em ensino-aprendizagem de língua estrangeira: os estudantes preferem aulas em que lhes são possibilitadas situações para participar, interagir, falar, debater, apresentar... ou seja, eles preferem "aulas com interação". Apesar de Gramática ter sido apontada pelos estudantes como a maior dificuldade para aprender português, a opção aula com exercício de gramática foi indicada por apenas $17 \%$ dos participantes, aparecendo somente em $3^{\circ}$ lugar dentre os tipos de aula que os estudantes consideram melhor para aprender essa língua-alvo, atrás ainda de "aula com vídeos e áudios sobre cultura brasileira", indicada por $22 \%$ dos estudantes que participaram da pesquisa, conforme mostra o gráfico 2 a seguir:

Gráfico 2: Participação dos estudantes

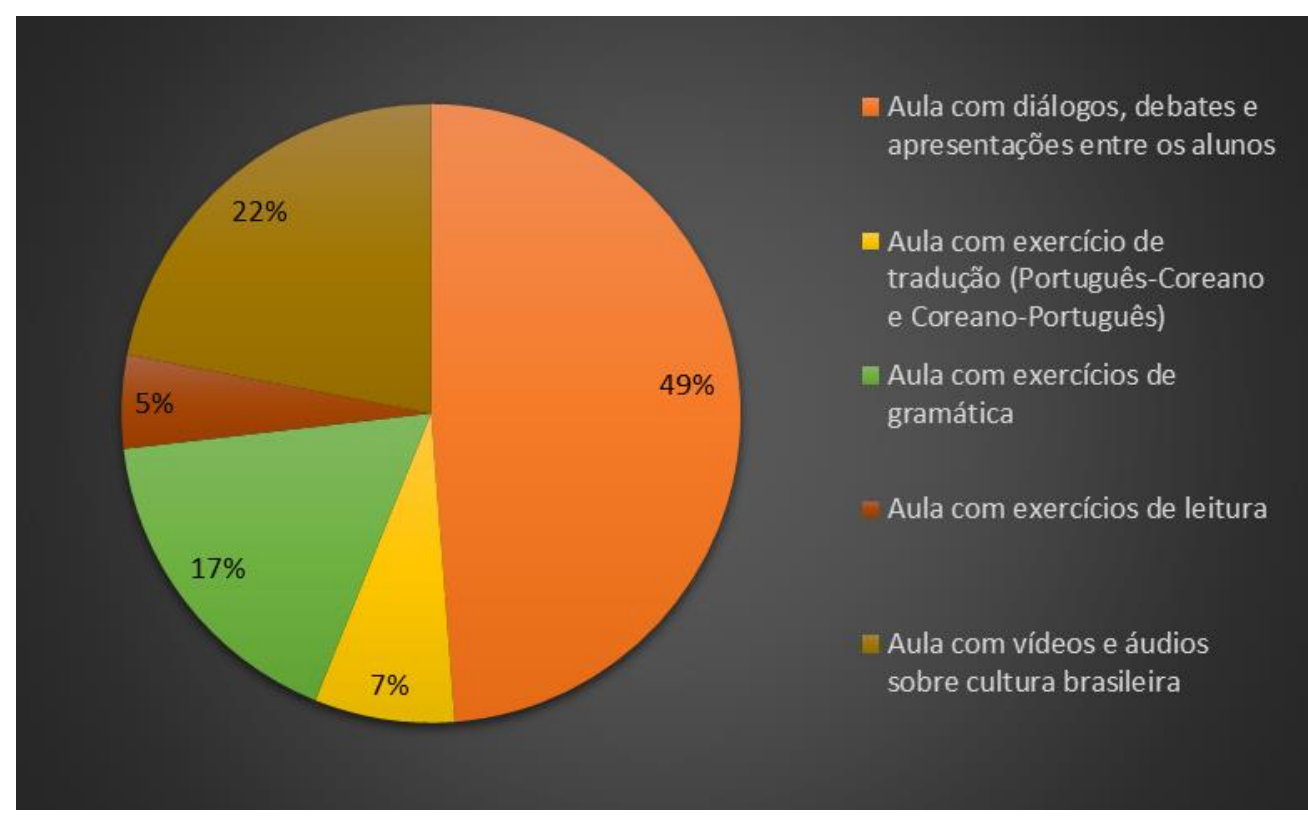

Fonte: Autoria própria 


\section{Considerações finais}

A partir da observação e análise dos dados coletados, podemos refletir sobre a nossa prática em sala de aula a fim de favorecer o ensino-aprendizagem de português como língua estrangeira e de cultura brasileira para estudantes do contexto universitário coreano. Os dados sugerem que o ensino comunicativo parece estar em consonância com a expectativa dos estudantes coreanos por uma aula que promova o protagonismo do aprendiz de língua estrangeira, levando-o a apropriar-se do seu próprio processo de aprendizagem.

No início da década de 1970, o ensino comunicativo foi proposto como resposta à insatisfação generalizada em relação a abordagens formais - ou "formalistas" - no ensino-aprendizagem de língua estrangeira, que não atendiam às necessidades crescentes de um mundo em pleno processo de globalização. O EC, em todas as suas vertentes, sempre destacou a centralidade do papel do aluno no processo de aprendizagem, suas necessidades e seus interesses (SAVIGNON, 2007, apud MATTOS, 2010, p.137). É preciso, portanto, partirmos sempre das necessidades do aprendiz de língua estrangeira e, ao mesmo tempo, considerarmos a diversidade de conhecimentos (culturais, linguísticos, comunicativos, etc.), já trazidos por ele para a sala de aula de PLE.

Para isso, na organização do trabalho didático em sala de aula, o professor precisa considerar os objetivos que pretende alcançar em relação às necessidades dos aprendizes. Ao indicarem os aspectos gramaticais como o maior dificultador para o desenvolvimento da sua proficiência em língua portuguesa, os próprios estudantes coreanos sinalizaram para nós, professores de PLE, uma de suas necessidades reais e, como professores, precisamos ouvi-los e organizarmos o trabalho em sala de aula de modo a atender a essa necessidade.

Isso não significa, contudo, voltarmos a uma abordagem estruturalista da língua, enfocando itens gramaticais descontextualizados - ou seja, fora do texto e da situação comunicativa; significa modelarmos as atividades organizativas que preparamos com base nos pressupostos de um ensino comunicativo (apontado pelos estudantes como favorável para o seu processo de aprendizagem), de modo a contemplar os tópicos gramaticais que ainda se apresentam como necessidades para esses estudantes.

Para tanto, esses tópicos gramaticais devem ser trabalhados com os estudantes aprendizes até que eles tenham se apropriado tanto da forma correta quanto do uso 
adequado desses elementos, sem, contudo, perdermos de vista, nesse processo, a compreensão que se tem de um ensino-aprendizagem de língua estrangeira a partir de uma perspectiva comunicativa. Ou seja, uma perspectiva em que o objetivo da aula de língua estrangeira seja o desenvolvimento da competência comunicativa (usar para aprender e aprender para usar) ${ }^{5}$, na qual a língua deve ser concebida como recurso dinâmico mobilizado para a criação de significados e o ensino deve realizar-se por meio de atividades que envolvam situações reais de comunicação. Mesmo no tradicional contexto coreano, no qual o domínio da forma gramatical configura-se como uma demanda tanto pedagógica quanto social, a aula de PLE precisa oferecer ao estudante aprendiz a possibilidade de mover-se entre dois mundos, aproximando-os: o Brasil e a Ásia, o Ocidente e o Oriente. Essa mobilidade e essa aproximação só serão possíveis se formos, professores e aprendizes, muito além da gramática.

\section{REFERÊNCIAS}

\section{GLOSSÁRIO CEALE. Termos de alfabetização, leitura e escrita para educadores.}

Disponível em:

<http://ceale.fae.ufmg.br/app/webroot/glossarioceale/verbetes/competenciacomunicativa>. Acesso em: 11 nov. 2017.

MATTOS, A. M. de A.; VALÉRIO, K. M. Letramento crítico e ensino comunicativo: lacunas e interseções. RBLA, Belo Horizonte, v. 10, n. 1, p. 135-158, 2010.

NORTON, B. Critical literacy and international development. Critical Literacy: theories and practices, v. 1, n. 1, p. 6-15, 2007.

VANZELLI, J. C.; CHAVES, I. O.; TEIXEIRA, H. G. (Ed.). Estudos brasileiros na Ásia. 1 ed. Viçosa: Editora UFV, 2017.

\section{Como referenciar este artigo}

FRANCISCO, D. L. Aulas com interação: ensinando (e aprendendo) língua portuguesa e cultura brasileira na Coreia do Sul. Rev. EntreLínguas, Araraquara, v.4, n.1, p. 133142, jan./jun., 2018. E-ISSN: 2447-3529. DOI: 10.29051/rel.v4.n1.2018.11179.

Submetido em: 09/03/2018

Aprovado em: 12/04/2018

5 “A competência comunicativa é a capacidade do usuário da língua de produzir e compreender textos adequados à produção de efeitos de sentido desejados em situações específicas e concretas de interação comunicativa. Portanto, é a capacidade de utilizar os enunciados da língua em situações concretas de comunicação.”. GLOSSÁRIO CEALE. Termos de alfabetização, leitura e escrita para educadores. 